\begin{tabular}{c}
\hline Review of \\
ECONOMICS \\
and \\
INSTITUTIONS \\
\hline
\end{tabular}

\title{
The Relationship Between Health and Growth: When Lucas Meets Nelson-Phelps
}

\author{
Philippe Aghion \\ Harvard University
}

\author{
Peter Howitt \\ Brown University
}

\author{
Fabrice Murtin ${ }^{凶}$ \\ OECD
}

\begin{abstract}
This paper revisits the relationship between health and growth in light of modern endogenous growth theory. We propose a unified framework that encompasses the growth effects of both the rate of improvement of health and the level of health. Based on cross-country regressions over the period 1960-2000, where we instrument for both variables, we find that a higher initial level and a higher rate of improvement in life expectancy both have a significantly positive impact on per capita GDP growth. Then, restricting attention to OECD countries, we find supportive evidence that only the reduction in mortality below age forty generates productivity gains, which in turn may explain why the positive correlation between health and growth in cross-OECD country regressions appears to have weakened since 1960.
\end{abstract}

JEL classification: E0, I10, O10, 015

Keywords: economic growth, endogenous growth theory, health, convergence, Bayesian econometrics.

This research was commissioned by the LIR, which we gratefully acknowledge. We are most grateful to Brigitte Calle and Agnes Renard-Viard for their continuous support and encouragements, and to Daron Acemoglu, Simon Johnson, Peter Lorentzen and Romain Wacziarg for kindly sharing their data. This work benefited a lot from Aart Kraay's numerous suggestions. We also thank Gabrielle Fack for her help at an earlier stage of the project, and David Canning, Esther Duflo, Michael Kremer, Sophocles Mavroeidis, Chris Papageorgiou, Thomas Piketty, David Weil for helpful comments. The findings, interpretations, and conclusions expressed in this paper are entirely those of the authors and in particular they do not necessarily represent the views of the OECD.

Corresponding author. Address: OECD, Economics Department, 2 rue André Pascal, 75775 Paris Cedex 16, France (Phone: +33 1452476 08; Email: Fabrice.Murtin@oecd.org)

Recommended Citation

Aghion, P., Howitt, P., Murtin, F. (2011). The Relationship Between Health and Growth: When Lucas Meets Nelson-Phelps. Review of Economics and Institutions, 2(1), Article 1. doi: 10.5202/rei.v2i1.1. Retrieved from http://www.rei.unipg.it/rei/article/view/22 


\section{Introduction}

Does health enhance (per capita) GDP and GDP growth? This question is of primary importance, in particular in current debates on the costs and benefits of new health programs. For example, public support for more universal health coverage is obviously affected by whether or not people believe that improved health raises growth. While left-leaning politicians would still advocate such programs even if they were not growth-enhancing, the programs would gain consensus if it could be shown, as it has been for education, that improving health is another way to increase a country's growth potential.

Basic economic intuition, supported by partial empirical evidence, suggests that health should matter for growth. First, individuals with higher life expectancy are likely to save more, and savings in turn feed back into capital accumulation and therefore into GDP growth as shown for instance by Zhang et al. (2003). Second, individuals with higher life expectancy are likely to invest more (or to have their parents invest more) in education, which in turn should be growth-enhancing. ${ }^{1}$ In an environment marked by low child mortality, parents are likely to choose a low level of fertility ${ }^{2}$, which limits the growth of total population and supports per capita GDP growth. Finally, and more directly, healthier individuals are typically more productive, better at creating and adapting to new technologies and generally more able to cope with the rapid changes characteristic of a high growth environment. ${ }^{3,4}$

However, the existing macroeconomic literature on health and income/growth appears to provide mixed answers to the above question. On the one hand, Acemoglu and Johnson (2007), henceforth AJ, who regress (per capita) income growth on the increase in life expectancy between 1940 and 1980, report a negative impact of increased life expectancy on per capita income, which they interpret as reflecting a Malthusian effect of (health induced) population growth

\footnotetext{
${ }^{1}$ Miguel and Kremer (2004) as well as Jayachandran and Lleras-Muney (2009) provide convincing microeconomic evidence that better health increases human capital investments.

${ }^{2}$ See Lee(2003) and Galor (2005) for a discussion of the demographic transition. Using a large panel of countries spanning over the late XIXth and XXth centuries, Murtin (2009) displays empirical evidence that child mortality has been significantly and positively associated with fertility.

${ }^{3}$ Howitt (2005) provides a framework for incorporating health improvements into an innovation-based growth model, which emphasizes the direct effects of health, especially early childhood health, on the pace of technological change.

${ }^{4}$ That the level of life expectancy should matter for growth is also consistent with recent work by Doppelhofer et al. (2004) and Cervellati and Sunde (2009). The latter show that the level of initial life expectancy is a strong predictor of the growth rate in fertility. As a result, introducing initial life expectancy inside the regression helps control for the effect of demographic transition. In particular the late decline in fertility should reduce population growth and thereby mitigate the negative Malthusian effect of growth in life expectancy upon per capita GDP growth. The former use Bayesian averaging models techniques to show that the initial level of life expectancy is one of the most robust determinant of economic growth.
} 
on per capita income..$^{5}$ On the other hand, Lorentzen, McMillan and Wacziarg (2008), henceforth LMW, who regress per capita GDP growth on the level of life expectancy as measured by average child and adult mortality rates over the period 1960-2000, ${ }^{6}$ report a strongly negative effect of mortality rates, i.e. a strongly positive effect of life expectancy, on income growth. ${ }^{7}$

In this paper we show that the key to understanding the apparent contradiction between these two papers, is convergence in life expectancy. As we document below, growth of life expectancy is strongly negatively correlated with initial life expectancy across countries, over both the 1940-80 and 1960-2000 periods. AJ show that countries where life expectancy grew rapidly did not tend to experience more rapid income growth; but what we argue in this paper is that their negative finding mainly reflects the fact that these same countries also typically started with lower initial levels of health. The omission of initial life expectancy from the RHS of their growth regressions generates a downward bias on the estimated coefficients, which in turn explains the negative regression coefficients they obtain between growth in life expectancy and growth in per capita income.

More specifically, we combine the so-called Lucas (or Mankiw-Romer-Weil) approach whereby output growth should be correlated with the rate of improvement in human capital, with the so-called "Nelson-Phelps" approach whereby a higher level of health should spur growth by facilitating technological innovation and/or technological adoption, and we look at the joint effect of health and health accumulation on economic growth, much in the spirit of Krueger and Lindahl (2001), who performed a similar exercise when looking at the effect of education on growth. We first develop a unified framework for analyzing the relationship between health and growth, which embeds both level and accumulation effects. Then moving to the empirical part, we run crosscountry growth regressions over the period 1960-2000 (the same period as in Krueger-Lindahl) and show that over that period both the level and the accumulation of health have significant positive effects on growth of per capita GDP, even when we use the LMW instruments for the level and accumulation of life expectancy. We also show that these instruments pass such standard tests as

\footnotetext{
${ }^{5}$ To instrument for the growth of life expectancy, AJ exploit the wave of health innovations that occurred as of the 1950s and affected all countries worldwide: more precisely, they use the pre-intervention distribution of mortality from 15 diseases and the dates of global interventions to construct a country-varying instrument for life expectancy.

${ }^{6}$ LMW use seventeen instruments for these two mortality indicators: a malaria ecology index - originally developed by Sachs et al. (2004) - which captures the exogenous portion of malaria incidence, twelve climate variables, and four geographic features of countries, which are unlikely to be affected by human activity and more particularly by income levels or growth rates.

${ }^{7}$ In addition, LMW disentangle the negative effects of mortality on investment and human capital accumulation from its positive effect on the fertility rate, and they find that investment and fertility are the strongest channels underlying the positive effect of health on growth.
} 
the Hansen test for joint exogeneity of instruments and the Stock-Yogo test for weak instruments. Our basic results are further confirmed by a robustness analysis which uses Bayesian techniques to assess the influence of potential endogeneity biases on OLS estimates. Testing the influence of various priors on the probability distribution of the correlation between residuals and explanatory variables, we find a robust positive effect of initial life expectancy and a somewhat less robust effect of life expectancy growth. Together our results also suggest that the omission of initial life expectancy, or the omission of the growth of life expectancy, from the RHS of our growth regressions may generate a downward bias on the estimated coefficients.

Finally, we look more closely at the relationship between health and growth across various types of countries and focus on OECD countries. We find a weaker relationship over the contemporary period, and interpret this finding as reflecting an age-specific productivity effect of health. Indeed, as of 1960, a large share of the growth of life expectancy at birth appears to be related to a reduction in mortality at old age, but we find that it is mostly the decrease in the mortality of individuals aged forty or less that matters for growth.

The paper is structured as follows. Section 2 lays out the theoretical framework. Section 3 describes the data and the empirical methodology and presents our basic cross-country regression results. Section 4 discusses these results along three dimensions; first it analyzes the trade-off between multicollinearity and endogeneity bias that is created by convergence in life expectancy; then it presents a Bayesian analysis of endogeneity bias in our OLS results, and finally it presents the results from cross-OECD panel regressions. Section 5 concludes by summarizing our results and suggesting avenues for future research.

\section{A Simple Theoretical Framework}

In this section we sketch a simple model where the accumulation and level of health both matter for growth. Final output is produced with human capital (health) so that per capita GDP is given in any period by

$$
Y=A H^{\beta}
$$

where $0<\beta<1, H$ is the current stock of human capital, and $A$ is a productivity parameter. Intuitively, a higher level of health makes labor more productive and therefore increases the amount of efficiency labor in the economy. Using lower case letters to denote natural logs, we have

$$
y=a+\beta h
$$

Equation (1) embodies the Lucas effect of human capital, which implies that the accumulation of health (namely $\dot{h}$ ) should have a positive effect on output growth $(\dot{y})$. 
Productivity itself evolves over time according to the Nelson-Phelps equation

$$
\dot{a}=\theta(\bar{a}-a)+\alpha h+\delta
$$

where $\bar{a}$ is the log of the current world frontier productivity and where $\theta, \alpha, \delta$ are all constants. Intuitively, the higher the stock of health and therefore the higher $h$, the higher is the level of cognitive ability in the population, and therefore the easier it is for current productivity $a$ to catch up with the "current world best practice" $\bar{a}$.

Combining (1) and (2), we see that growth of per capita GDP should depend upon both the level and accumulation of human capital, according to:

$$
g=\dot{y}=\theta(\bar{a}-a)+\alpha h+\beta \dot{h}+\delta
$$

Alternatively, we can express this growth equation as

$$
g=\delta+\theta \bar{a}-\theta y+(\alpha+\beta \theta) h+\beta \dot{h}
$$

which says that growth of per capita GDP should depend negatively upon its initial level, positively upon the level and accumulation rate of health, and positively upon current world productivity.

We test this equation in the remaining part of the paper, using cross country panel data. Note that if $\theta=0$ then growth cannot depend on all three variables $(a, h, \dot{h})$ or $(y, h, \dot{h})$, just on two of them.

\section{Empirical Analysis}

In this section, we describe our empirical methodology and data, and then we present and discuss the empirical results.

\subsection{Empirical Methodology}

In line with equation (3), we will estimate the equation:

$$
\Delta \log y_{i}=a+b \Delta \log L E_{i}+c \log L E_{i, 0}+d \log y_{i, 0}+u_{i}
$$

where $\Delta \log y_{i}$ is the change per year in the log of per capita GDP in country $i$ over a given time period, multiplied by $100 ; \Delta \log L E_{i}$ is the change per year in the log of life expectancy in that country over the same period, also multiplied by $100 ; \log L E_{i, 0}$ is the $\log$ of life expectancy at the beginning of the period; $\log y_{i, 0}$ is initial $\log$ per capita GDP and $u_{i}$ is a residual term. ${ }^{8}$ Equation (4) embeds the pure Lucas approach if one assumes that $\mathrm{c}=0$, as well as the pure Nelson-Phelps

${ }^{8}$ We interpret $\Delta \log y_{i}$ and $\Delta \log L E_{i}$ as annual growth rates measured in percentage points, and refer to them as "growth of per capita GDP" and "growth of life expectancy" respectively. 
approach if $b=0$. Each regression shown in this section will be run three times: with the Lucas restriction $c=0$, with the Nelson-Phelps restriction $b=0$, and without either restriction.

We will provide both OLS and IV estimations for all our cross-country regressions, which span the period 1960-2000. Measuring growth over a forty year period enables us to reduce measurement errors affecting growth of per capita GDP or life expectancy. Hauck and Wacziarg (2009) show that panel fixedeffects estimators typically magnify this problem of measurement error; hence our emphasis on cross-country regressions. However, when restricting attention to OECD countries, we will exploit the time dimension and run panel regressions using ten-year periods in order to avoid potential small sample size issues.

\subsection{Data and Summary Statistics}

We exploit two databases: the LMW data that cover 96 countries over the period 1960-2000, ${ }^{9}$ and the OECD (2009) health database that provides information on life expectancy at various ages $(0,40,60$ and 80 years) across OECD countries from 1960 onwards.

\section{Table 1 - Descriptive Statistics}

\begin{tabular}{lccc}
\hline & \multicolumn{3}{c}{ Lorentzen-McMillan-Wacziarg sample } \\
\cline { 2 - 4 } & $\mathbf{1 9 6 0}$ & $\mathbf{2 0 0 0}$ & $\mathbf{1 9 6 0 - 2 0 0 0}$ \\
\hline Developed countries & & & \\
GDP per capita & 7820 & 22802 & +14982 \\
Life expectancy at birth & 68.3 & 77.5 & +9.2 \\
$\mathrm{~N}$ & 25 & 25 & 25 \\
Developing countries & & & \\
GDP per capita & 2033 & 4315 & +2282 \\
Life expectancy at birth & 47.6 & 59.9 & +12.3 \\
$\mathrm{~N}$ & 71 & 71 & 71 \\
\hline
\end{tabular}

Table 1 summarizes the main data sample drawn from LMW. The Table shows average per capita GDP and average life expectancy among high-income

\footnotetext{
${ }^{9}$ The per capita GDP data, the child and adult mortality rates, the life expectancy data, as well as various sources for their 17 instrument variables, are all drawn from the World Bank's World Development Indicators (2004) data set. As quoted from LMW, the malaria ecology index combines "the presence of different mosquito vector types and the human biting rate of the different mosquito vectors" (Sachs et al., 2004). LMW add eleven climate variables borrowed from the Koeppen-Geiger climate zones classification: tropical rainforest climate, its monsoon variety, tropical savannah climate, steppe climate, desert climate, mild humid climate with no dry season, mild humid climate with a dry summer, mild humid climate with a dry winter, snowy-forest climate with a dry winter, snowyforest climate with a moist winter and highland climate. Finally, they add a variable measuring the proportion of land with more than five days of frost per month in winter, as well as the following geographical variables: the distance of a country's centroid from the equator, the mean distance to the nearest coastline, the average elevation, and the log of land area.
} 
countries and among low/middle-income countries from the LMW sample over the period $1960-2000 .^{10}$ Not surprisingly, we see that high-income countries achieved much larger gains in per capita GDP but smaller increases in life expectancy than low/middle-income countries over this period. To facilitate discussion of the quantitative importance of our coefficient estimates, Table 1 also includes data on the Sub Saharan subsample of LMW.

\subsection{Cross Country OLS Regressions}

Table 2 shows the results of cross country OLS regressions. Columns I and II reproduce the LMW methodology. ${ }^{11}$ Regressing growth of per capita GDP on the level of health as measured by the average child and adult mortality rates over the 1960-2000 period, we find a negative coefficient on these mortality indicators. If we believe the estimates in column II indicate causality, adding up the effects of child and adult mortality as well as cross-country convergence, accounts for a growth gap of 2.55 percentage points between Sub-Saharan Africa and highincome countries. ${ }^{12}$ Next, columns III and IV show that the regression coefficients are not significantly affected when substituting child and adult mortality rates in 1960 for their average values over the period, in other words when moving to a more standard Nelson-Phelps approach. This result is not so surprising as mortality rates evolve slowly over time: for example, the correlation between the 1960 adult mortality rate and its grand average over the 1960-2000 period is equal to 0.93 . Columns V and VI focus on a different explanatory variable, namely the $\log$ of life expectancy, while still adopting a Nelson-Phelps approach. Doing so makes the analysis more comparable with that in AJ, which similarly looks at life expectancy rather than mortality rates. Qualitatively, choosing life expectancy rather than mortality indicators for health does not seem to make a big difference since we find that initial $1960 \log$ of life expectancy ${ }^{13}$ is significantly and positively correlated with per capita GDP growth. In addition, the magnitude of the regression coefficient is broadly comparable to what we obtain using mortality rates instead. ${ }^{14}$

\footnotetext{
${ }^{10}$ Life expectancy has been defined as the non-weighted average of male and female life expectancy.

${ }^{11}$ See LMW, page 93, Table 4, column 1.

${ }^{12}$ With respectively 50 and 17 deaths per 1000 adults in Sub-Saharan Africa and highincome countries, and accounting for the LMW normalization of adult mortality, the latter variable vehicles a gap of $5 \times(0.5-0.17)=1.65$ percentage points of annualized growth all along the period. As Sub-Saharan 1960 infant mortality was about 150 deaths per 1000 births, versus roughly 20 in developed countries, infant mortality implies a gap of $20.85 \times(0.15-0.02)=2.7$ percentage points of growth. On the other hand, according to Table 1, the convergence effect would imply a catch-up of about $1.03 \times(\log (7820 / 1354))=$ 1.8 percentage points. The combined effect of convergence, adult and child mortality therefore amounts to a growth gap of 1.65+2.7-1.8 $=2.55$ percentage points.

${ }^{13}$ Similar results obtain if we simply use life expectancy as our health variable.

${ }^{14}$ Indeed, according to the data in Table 1, the gap in life expectancy between a developed country and a Sub-Saharan African country would entail a $6.53 \times$ $\log (68.3 / 39.2)=3.6$ percentage points gap in growth rates. Convergence would imply a
} 
Columns VII and VIII introduce the Lucas approach, whereby one regresses growth of per capita GDP on growth of life expectancy. We find a non-significant coefficient of the growth of life expectancy, even after controlling for initial log per capita GDP. In substance, this result is consistent with AJ's findings of a nonpositive effect of life expectancy growth on per capita GDP growth, even though here we look at different time periods. Finally, columns IX and $X$ combine the Lucas and Nelson-Phelps approaches, and we find that there is a strong, positive and highly significant coefficient of both the initial level and growth rate of life expectancy over the period.

Table 2 - Nelson-Phelps versus Lucas Growth Regressions 1960-2000 - OLS Estimates

\begin{tabular}{|c|c|c|c|c|c|c|c|c|c|c|}
\hline & \multicolumn{2}{|c|}{$\begin{array}{l}\text { Lorentzen-McMillan- } \\
\text { Wacziarg results }\end{array}$} & \multicolumn{4}{|c|}{ Nelson-Phelps variant } & \multicolumn{2}{|c|}{$\begin{array}{l}\text { Acemoglu- } \\
\text { Johnson/Lucas } \\
\text { approach }\end{array}$} & \multicolumn{2}{|c|}{ Combined approach } \\
\hline & 1 & II & III & IV & $\mathrm{V}$ & $\mathrm{VI}$ & VII & VIII & $\mathrm{IX}$ & $\mathrm{x}$ \\
\hline & \multicolumn{10}{|c|}{ Dependent Variable: Annual Growth in Log GDP per capita (in percentage points) } \\
\hline $\begin{array}{l}\text { Average adult } \\
\text { mortality } \\
1960-2000\end{array}$ & $\begin{array}{l}-2.89 * \\
(1.47)\end{array}$ & $\begin{array}{c}-5.06 * * * \\
(1.38)\end{array}$ & -- & -- & -- & -- & -- & -- & -- & -- \\
\hline $\begin{array}{l}\text { Average infant } \\
\text { mortality } \\
1960-2000\end{array}$ & $\begin{array}{c}-11.61^{* *} \\
(4.54)\end{array}$ & $\begin{array}{c}-20.85 * * * \\
(4.55)\end{array}$ & -- & -- & -- & -- & -- & -- & -- & -- \\
\hline $\begin{array}{lr}\text { Initial } & \text { adult } \\
\text { mortality } & 1960\end{array}$ & -- & -- & $\begin{array}{l}-1.81 \\
(1.53)\end{array}$ & $\begin{array}{c}-4.12 * * * \\
(1.51)\end{array}$ & -- & -- & -- & -- & -- & -- \\
\hline $\begin{array}{l}\text { Initial infant } \\
\text { mortality } 1960\end{array}$ & -- & -- & $\begin{array}{l}-8.84+ \\
(3.37)\end{array}$ & $\begin{array}{c}-13.72 * * * \\
(3.75)\end{array}$ & -- & -- & -- & -- & -- & -- \\
\hline $\begin{array}{l}\text { Initial log life } \\
\text { expectancy } \\
1960\end{array}$ & -- & -- & -- & -- & $\begin{array}{c}3.42 * * * \\
(0.48)\end{array}$ & $\begin{array}{c}6.53 * * * \\
(0.87)\end{array}$ & -- & -- & $\begin{array}{c}4.15^{* * *} \\
(0.49)\end{array}$ & $\begin{array}{c}7.82 * * * \\
(0.93)\end{array}$ \\
\hline $\begin{array}{l}\text { Growth in life } \\
\text { expectancy } \\
1960-2000\end{array}$ & -- & -- & -- & -- & -- & -- & $\begin{array}{c}0.70 \\
(45.72)\end{array}$ & $\begin{array}{c}28.63 \\
(46.40)\end{array}$ & $\begin{array}{c}124.4^{* * *} \\
(44.7)\end{array}$ & $\begin{array}{c}154.25^{* * *} \\
(38.3)\end{array}$ \\
\hline $\begin{array}{l}\text { Initial log GDP } \\
\text { per capita } \\
1960\end{array}$ & --- & $\begin{array}{c}-1.03 * * * \\
(0.19)\end{array}$ & -- & $\begin{array}{c}-0.84 * * * \\
(0.21)\end{array}$ & -- & $\begin{array}{c}-1.02 * * * \\
(0.23)\end{array}$ & -- & $\begin{array}{c}0.40 * * * \\
(0.23)\end{array}$ & -- & $\begin{array}{c}-1.14^{* * *} \\
(0.22)\end{array}$ \\
\hline $\mathrm{R}^{2}$ & 0.40 & 0.57 & 0.27 & 0.37 & 0.31 & 0.44 & 0.00 & 0.06 & 0.37 & 0.54 \\
\hline $\mathrm{N}$ & 94 & 94 & 94 & 94 & 96 & 96 & 96 & 96 & 96 & 96 \\
\hline
\end{tabular}

Notes: Robust standard errors; ***(respectively ** and *) represents significance at $1 \%$ (resp. 5\% and 10\%).

The comparison between columns V and VII, or between columns VI and VIII, shows that the Lucas and Nelson-Phelps approaches lead to different conclusions on the country samples, as they respectively display significant and insignificant correlations between (improved) life expectancy and per capita GDP growth. When combining the two approaches, that is, when regressing per capita GDP growth on both the initial level and the increase in life expectancy over the period, we find that: (i) both the accumulation and initial level in life expectancy are positively associated with income growth; ii) the magnitude of the coefficient

catch-up of 1.8 percentage points. Thus, overall, this regression can explain up to a 1.8 percentage point growth gap. 
on initial life expectancy is larger than that obtained when following a pure Nelson-Phelps approach. In fact, the combined approach corrects for biases arising from the omitted variable problems in both the pure Lucas and pure Nelson-Phelps strategies, as witnessed by the increase in explained variance when regressing growth over both the level of and increase in life expectancy.

The magnitudes of our coefficient estimates reinforce the point made by LMW, namely that health seems to have an important effect on growth: for instance, if we use the estimates in column X of Table 2, the gap in 1960 life expectancy between developed and developing countries shown in Table 1 implies a difference in average per capita GDP growth of $7.82 \times \log (68.3 / 47.6)=$ 2.8 percentage points between 1960 and 2000. The effect of initial life expectancy thus plays in favor of the developed countries. On the other hand, the average growth of life expectancy over that period has been slightly faster in developing countries, which in turn gives developing countries a per capita GDP growth advantage equal to $154.25 \times(\log (59.9 / 47.6)-\log (77.5 / 68.3)) / 40=0.40$ percentage points. Combining the level and accumulation effects, our approach implies that differences in health between developed and developing countries over that period account for an annual growth gap of 2.8-0.4 $=2.4$ percentage points.

\subsection{Instrumentation}

To address endogeneity issues, we instrument for both the initial level and growth of life expectancy using the LMW instruments; i.e., the Malaria Ecology index developed by Sachs et al. (2004) and the sixteen climatic and geographical variables. The results are displayed in Table $3,{ }^{15}$ which reports the corresponding F-statistics and Shea's $R^{2}$ statistics from first-stage regressions. These statistics are high, with for instance F-test p-values lying below 0.01. In addition, we run the Hansen-J test of overidentifying restrictions, which is robust to the presence of heteroskedasticity and autocorrelation. In all regressions but that shown in column I, we fail to reject the null hypothesis of the joint exogeneity of our instrumental variables, which suggests that our geographical and climate variables operate through the life expectancy channel to impact per capita GDP growth. ${ }^{16}$ As a further robustness check, we run the Stock-Yogo tests of weak instruments, as several climatic and geographical variables are never significant in first-stage regressions. On columns I and III (respectively II and IV), the test rejects the null hypothesis that the relative bias on IV estimates caused by weak instruments is at maximum equal to $20 \%$ (respectively $10 \%$ and $30 \%$ ). However,

\footnotetext{
${ }^{15}$ As we focus on the 1960-2000 period, we cannot use AJ's predicted mortality at initial date as an instrument for growth of life expectancy because many global health interventions have already taken place by 1960 . Also, the use of this instrument relies on the assumption that initial mortality - in almost equal terms, initial life expectancy - does not matter for subsequent growth in GDP per capita, an assumption that amounts to imposing the pure Lucas approach a priori. Relaxing this assumption by itself precludes the use of the $\mathrm{AJ}$ instrument.

${ }^{16}$ However, it should be noted that the Hansen test is only valid conditionally on the existence of some - in this case at least two - valid instruments among the total set of instruments.
} 
this result is obtained using the full set of LMW instruments. When poor instruments are excluded as in columns V and VI, the Stock-Yogo test rejects the null hypothesis of a maximal relative bias of magnitude $10 \%$.

We now briefly describe the substantive results in Table 3. Column I adopts the Lucas approach and shows an insignificant and negligible effect of the growth of life expectancy, thereby confirming the result found in former OLS regressions. Similarly, the IV approach validates the OLS result drawn from the Nelson-Phelps approach, namely that of a significant and positive impact of initial life expectancy as shown in column II. Next, instrumenting the combined regression in columns III and IV confirms our previous results from combined OLS regressions: namely, a positive and significant effect of both the initial level and growth of life expectancy on per capita GDP growth. Reducing the set of instruments hardly changes the results, except that in column $\mathrm{V}$ the coefficient of life expectancy growth loses significance, with a p-value now equal to 0.12 .

Table 3 - Impact of Life Expectancy on GDP per Capita 1960-2000 - IV Estimates

\begin{tabular}{|c|c|c|c|c|c|c|c|}
\hline & & \multirow{2}{*}{$\begin{array}{l}\text { Lucas } \\
\text { I }\end{array}$} & \multirow{2}{*}{$\begin{array}{c}\text { Nelson- } \\
\text { Phelps } \\
\text { II }\end{array}$} & \multicolumn{4}{|c|}{ Combined approach } \\
\hline & & & & III & IV & $\mathbf{V}$ & VI \\
\hline & \multicolumn{7}{|c|}{ Dependent Variable: Annual Growth in Log GDP per capita (in percentage points) } \\
\hline \multicolumn{2}{|c|}{ Growth in log life expectancy } & $\begin{array}{c}1.08 \\
(70.20)\end{array}$ & -- & $\begin{array}{c}141.69 * * \\
(71.80)\end{array}$ & $\begin{array}{c}184.48^{* * *} \\
(55.26)\end{array}$ & $\begin{array}{l}130.65 \\
(84.52)\end{array}$ & $\begin{array}{c}172.58^{* *} \\
(73.55)\end{array}$ \\
\hline \multicolumn{2}{|l|}{ Initial log life expectancy } & -- & $\begin{array}{c}3.73^{* * *} \\
(0.48)\end{array}$ & $\begin{array}{l}4.37+ \\
(0.51)\end{array}$ & $\begin{array}{c}9.10 * * * \\
(1.12)\end{array}$ & $\begin{array}{l}4.86^{\dagger} \\
(0.58)\end{array}$ & $\begin{array}{c}8.10 * * * \\
(1.15)\end{array}$ \\
\hline \multicolumn{2}{|l|}{ Initial log GDP per capita } & -- & -- & -- & $\begin{array}{c}-1.41 * * * \\
(0.26)\end{array}$ & -- & $\begin{array}{c}-1.20 * * * \\
(0.27)\end{array}$ \\
\hline \multicolumn{2}{|l|}{$\mathrm{N}$} & 90 & 90 & 90 & 90 & 91 & 91 \\
\hline \multicolumn{2}{|l|}{$R^{2}$} & 0.00 & 0.27 & 0.35 & 0.50 & 0.34 & 0.51 \\
\hline \multicolumn{2}{|l|}{ Shea R2 ( $\Delta$ log LE) } & 0.55 & & 0.56 & 0.58 & 0.16 & 0.16 \\
\hline \multicolumn{2}{|l|}{ Shea R2 (log LE $\left.{ }_{0}\right)$} & & 0.78 & 0.80 & 0.58 & 0.43 & 0.39 \\
\hline \multicolumn{2}{|l|}{ Hansen-J test $p$-value } & 0.00 & 0.13 & 0.24 & 0.21 & 0.92 & 0.52 \\
\hline \multicolumn{2}{|c|}{$\begin{array}{l}\text { F-statistics for Stock-Yogo test } \\
\text { of weak instruments }\end{array}$} & 9.11 & 50.48 & 7.84 & 5.26 & 8.08 & 7.95 \\
\hline \multirow{3}{*}{$\begin{array}{l}\text { Stock-Yogo critical values } \\
\text { for maximal IV relative } \\
\text { bias of respectively: }\end{array}$} & $10 \%$ & 11.50 & 11.50 & 10.96 & 10.96 & 7.56 & 7.56 \\
\hline & $20 \%$ & 6.39 & 6.39 & 6.17 & 6.17 & 5.57 & 5.57 \\
\hline & $30 \%$ & 4.59 & 4.59 & 4.48 & 4.48 & 4.73 & 4.73 \\
\hline \multicolumn{2}{|l|}{ Set of Instruments } & $M E^{1}+\mathrm{LMW}^{2}$ & $\mathrm{ME}^{1}+\mathrm{LMW}^{2}$ & $\mathrm{ME}^{1}+\mathrm{LMW}^{2}$ & $M E^{1}+\mathrm{LMW}^{2}$ & $\begin{array}{l}\mathrm{ME}^{1}+ \\
\text { Reduced } \\
\mathrm{LMW}^{3}\end{array}$ & $\begin{array}{l}\mathrm{ME}^{1}+ \\
\text { Reduced } \\
\mathrm{LMW}^{3}\end{array}$ \\
\hline \multicolumn{8}{|c|}{$\begin{array}{l}\text { Notes: All growth variables calculated as long differences. Robust standard errors; }{ }^{* * *} \text { (respectively ** and } \\
\left.{ }^{*} \text { ) represents significance at } 1 \% \text { (resp. } 5 \% \text { and } 10 \%\right) ; \\
{ }^{2} \text { Malaria Ecology developed by Sachs et al. (2004); } \\
{ }^{2} \text { Sixteen climatic and geographical instruments taken from Lorentzen et al. (2008); } \\
{ }^{3} \text { Three climatic variables capturing the share of land area with respectively tropical rainforest climate, }\end{array}$} \\
\hline
\end{tabular}


Both level and accumulation effects are found to be large in magnitude. As already emphasized by LMW, initial differences in health have heavily contributed to Africa's growth shortfall. Using column VI as a benchmark, the gap in life expectancy between rich countries and Sub Saharan Africa in 1960 entails a huge gap in per capita GDP growth of $8.1 \times \log (68.3 / 39.2)=4.5$ percentage points. The later gap is offset somewhat by the fact that the percentage growth in life expectancy shown in Table 1 was larger in Sub Saharan Africa than in rich countries, but this offset only amounts to 0.3 percentage points. According to these estimates the combined effect of the initial level and growth of life expectancy on the growth gap is 4.2 percentage points. This was compensated by a convergence effect linked to initial differences in income, which reduces it to an annual difference of $4.2-2.1=2.1$ percentage points of annual growth. ${ }^{17}$ Furthermore, this figure falls short of accounting for the HIV/AIDS impact, which has in some Sub Saharan countries lowered life expectancy to the standards of the 1950s. ${ }^{18}$

Overall, our results are in line with LMW's finding that the causal effect of health on growth is large. This result is supported by several microeconomic studies examining the consequences of disease eradication, including Bleakley $(2003,2007)$ and Bleakley and Lange (2009). In contrast, Weil (2007) estimates the macroeconomic impact of improvements in health observed at the microeconomic level, and argues that health effects are small. However, the latter analysis focuses on the impact of health upon workers' productivity, but abstracts from other economic dimensions (investment, fertility and so on). In that regard, Ashraf at al.(2008) analyze the channels though which mortality's reduction impacts on per capita GDP, and simulate the resulting income growth path. Their thoughtful analysis concludes that gains in income from health improvement should be observed only on the long run, but much of their finding hinges on the assumption that it takes 50 years for fertility to adjust to the decline in mortality. ${ }^{19}$ Even if the literature has acknowledged the fact that the decline in child mortality was not the main driver of fertility's transition, it remains a significant and important determinant. Accordingly, Murtin (2009) finds that child mortality has been a significant and positive determinant of fertility at a global level over the XXth century. He finds that child as well as adult mortality can account for two thirds of fertility's decline in Europe between 1870 and $1910 .^{20}$ This suggests that health has an immediate impact upon fertility, and consequently, that health improvement generates large per capita GDP growth.

\footnotetext{
${ }^{17}$ According to Table 1 the convergence effect equals $1.2 \times \log (7820 / 1354)=2.1$ percentage points.

${ }^{18}$ In South Africa, for example, life expectancy fell from 49.2 in 1960 to 47.8 in 2000, implying that differential growth in life expectancy raised the South African growth gap (relative to developed countries) by an average of $172.58 \times(\log (77.5 / 68.3)-$ $\log (47.8 / 49.2)) / 40=0.67$ annual percentage points.

${ }^{19}$ Actually, they find large income gains if the reduction in mortality triggers an immediate adjustment in fertility (see their simulation described by Figure 11).

${ }^{20}$ Other findings suggests that primary education of the adult population is the main determinant of fertility. Income is positively associated with fertility in early stages of
} 


\section{Discussion}

This section discusses four main issues: First, the multicollinearity versus omitted variable dilemma generated by convergence in life expectancy; second, the sensitivity of our estimates to the set of explanatory variables and to instrumental variables; thirdly, the robustness of our OLS estimates to endogeneity bias; and finally the correlations between growth and mortality by age when focusing on OECD countries.

\subsection{Convergence, Multicollinearity and the Omitted Variable}

\section{Bias}

Over both the 1940-1980 and the 1960-2000 periods, life expectancy has converged across countries over time. This is a well-known fact nicely analyzed by Becker at al. (2005). Thus, Figure 1 shows a powerful convergence effect of the initial $1940 \mathrm{log}$ of life expectancy on the growth of life expectancy over the period 1940-1980, in AJ's sample of countries. In turn, Figure 2 shows a somewhat weaker but still significant convergence effect over 1960-2000 in LMW's sample. More precisely, the correlation coefficient between the two variables in the 194080 sample is -0.95 , while in the $1960-2000$ sample it is a more moderate -0.46 .

\section{Figure 1 - The Convergence in Life Expectancy Between 1940 and 1980}

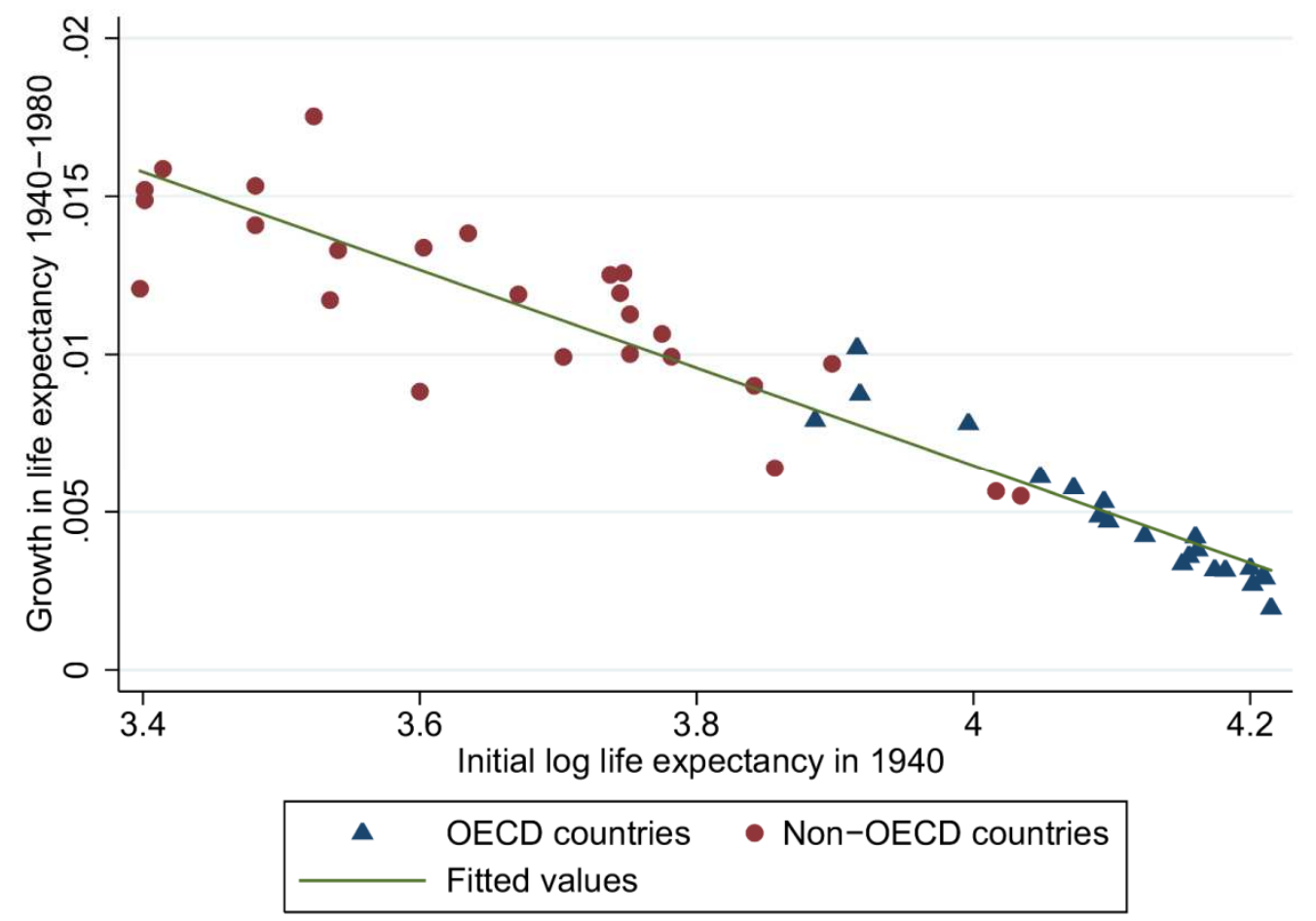

development, explaining why a Malthusian income effect eventually leads to early fertility increases. 
For reasons we detail below, too high a high level of correlation between the two regressors raises a dilemma. Either one decides to simply omit one variable from the regression, which may introduce an omitted variable bias, or both variables are included in the regression, which creates a multicollinearity problem. This dilemma further motivated us to focus on the 1960-2000 period, over which the correlation between the initial level and growth of life expectancy is lower.

\section{Figure 2 - The Convergence in Life Expectancy Between 1960 and 2000}

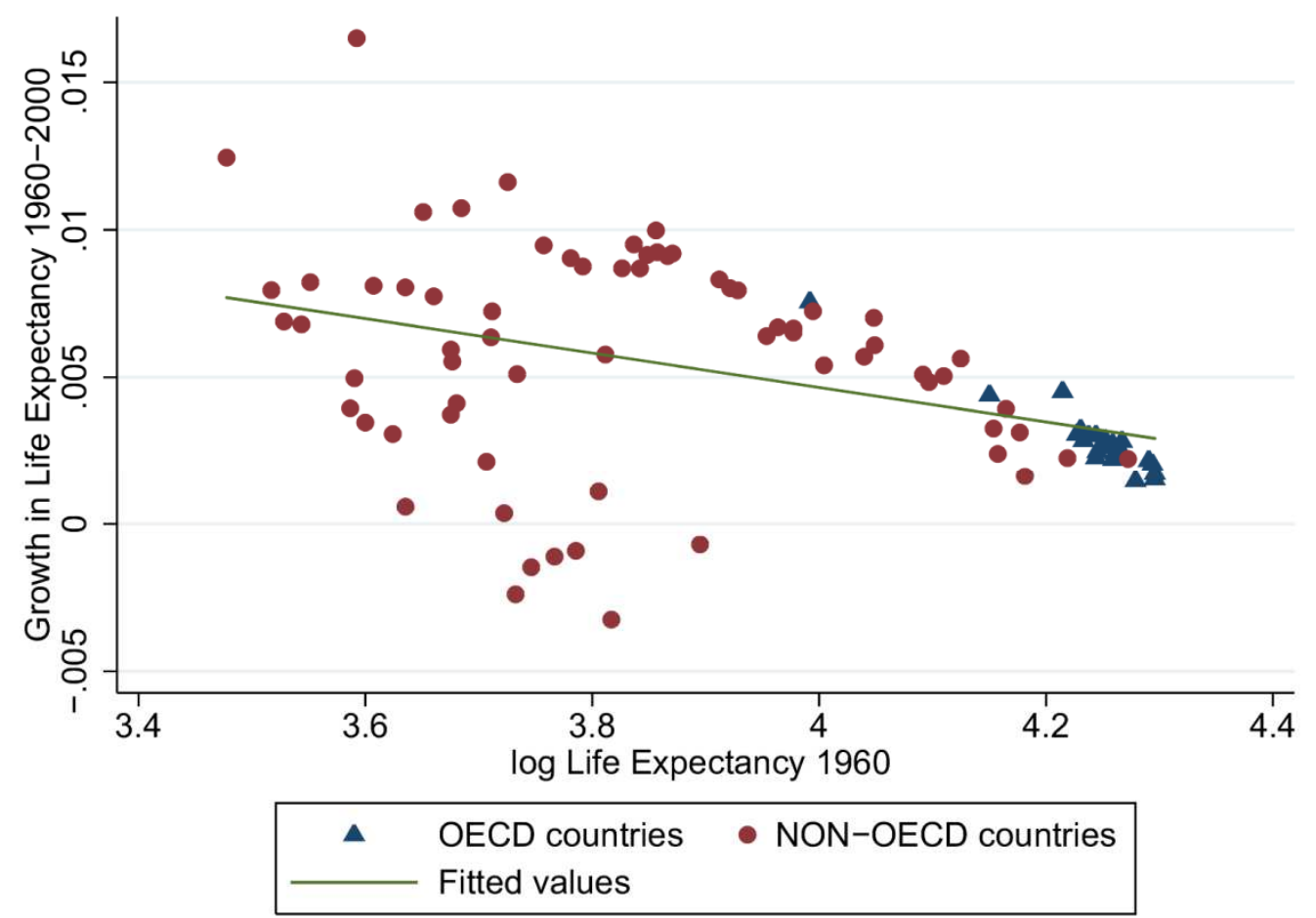

That the omission of one variable from our regression may lead to an underestimation of the other coefficient of interest has been mentioned in our introduction. In particular, over the period 1960-2000, compared to pure NelsonPhelps regressions, we find a higher magnitude for the effect of initial health on per capita GDP growth. And the conclusions from our combined regressions differ even more radically from what is suggested by pure Lucas regressions: these regressions show non-significant correlations between per capita GDP growth and the growth of life expectancy, thereby suggesting that health should have no significantly positive impact on per capita GDP growth. But suppose that, in line with our above model, growth is truly affected by both the level of health at the beginning of the period and by the improvement of health over the period. Thus the relationship between health, its accumulation, and per capita GDP growth, may be captured by regression equation (4). Now, let us also factor in the convergence in life expectancy phenomenon. From an econometric point of 
view, convergence in life expectancy can be captured through a linear regression of the form:

$$
\Delta \log L E_{i}=-\frac{1}{\rho} \log L E_{i, 0}+v_{i}
$$

where $v_{i}$ is an error term.

Plugging (5) into (4) yields:

$$
\begin{aligned}
\Delta \log y_{i} & =a+b \Delta \log L E_{i, 0}+c\left(-\rho \Delta \log L E_{i}+\rho v_{i}\right)+d \log y_{i, 0}+u_{i} \\
& =a+(b-c \rho) \Delta \log L E_{i, 0}+d \log y_{i, 0}+w_{i}
\end{aligned}
$$

In this equation, the coefficient of $\Delta \log L E_{i}$ picks up not only the effect of life expectancy accumulation $b$ but also the negative correlation between the accumulation of health (the improvement in life expectancy) and the initial level of health (or initial level of life expectancy). If the convergence coefficient $\rho$ is sufficiently high, it can lead to an insignificant or even negative sign for the coefficient $(b-c \rho)$ in the Lucas-type regression of per capita GDP growth on the accumulation of life expectancy. The fact that the negative correlation $\rho$ is large suggests that both the Lucas and the Nelson-Phelps approaches underestimate the effects of (improved) life expectancy on productivity growth, as both are contaminated by an omitted variable bias. However, over the 19602000 period this bias turns out to be relatively smaller in the pure Nelson-Phelps approach simply because of data statistical properties. ${ }^{21}$ Moving to the combined regression equation (4) thus generates estimates that are greater than those obtained in pure Nelson-Phelps regressions, and it restores the significance of life expectancy growth that was lost in the Lucas regressions. Overall, what our discussion illustrates, is that ignoring either of the two (level or accumulation) effects might generate potentially misleading policy conclusions, especially when explanatory variables display significant degrees of autocorrelation. ${ }^{22}$

On the other hand, including both the initial level and the growth of life expectancy in the regression may raise a multicollinearity issue. As pointed out to us by Aart Kraay, this issue is particularly serious when looking at the 19401980 period where the correlation between these two regressors is equal to -0.95 . One unpleasant and little-known consequence of multicollinearity is to magnify any endogeneity bias. Even if each variable had a negligible impact on growth, a low level of endogeneity and a high correlation between regressors could jointly

${ }^{21}$ From Table 2 one has $b=124.4, c=4.15$ and $1 / \rho=0.00645$. This conveys a negative omitted variable bias in the Lucas approach equal $-c \rho=-643.4$, and a negative omitted variable bias in the Nelson-Phelps approach equal to $-b / \rho=0.00645$.

${ }^{22}$ In theory, one could make the same case for average years of schooling inside growth regressions. However, as shown by Morrisson and Murtin (2009), convergence in education has been too weak over the 1960-2000 period to generate such a bias. 
create significant coefficients. For that reason, any combined OLS or IV estimation run over the 1940-1980 period, must be considered with suspicion. However, this multicollinearity issue is not so serious over the 1960-2000 period where the correlation between the initial level and the growth of life expectancy, is equal to -0.46. Put differently, the multicollinearity issue over that period, is no greater than in most existing cross-country growth regressions (for example the correlation between the growth of physical and in human capital has been of the same magnitude of 0.40 between 1960 and 2000).

Overall, the above discussion argues in favor of including both the growth and initial levels in life expectancy as RHS regressors in order to avoid an omitted variable bias. However, we do it over the sole $1960-2000$ period so as to avoid another econometric issue arising from multicollinearity.

\subsection{Robustness with Respect to Explanatory Variables and Instruments}

As the main purpose of this paper is to explain the contradictory results obtained by AJ and LMW regarding the effect of health on growth, we have chosen a set of explanatory variables common to both studies to ensure comparability. AJ focuses on the $1940-1980$ period during which little data is available (especially for the stock of physical capital) and they consequently use only one explanatory variable, the change in life expectancy. In contrast, LMW have run regressions where they control not only for health variables but also for other potential determinants of economic growth. Importantly, they find that health variables are still significant after controlling for several other factors (see their Tables 4, 5 and 7).

To evaluate the robustness of our results, we have introduced additional explanatory variables in our empirical framework. It comes as no surprise that the significance of health variables is unaltered as in LMW. As reported by Table 4 columns 2 and 4 where we control for an index in democracy, the rate of urbanization, population density, the log of population, openness and its interaction with population size, all variables found in LMW regressions, the significance of the growth and of the initial level of life expectancy are preserved in both OLS and IV regressions.

Moreover, we examine the robustness of our results to the choice of instrumental variables. Arguably, geography and climatic variables may have a direct impact on economic growth, so that their validity as instruments can be debated. However, we show on columns 5 and 6 (where Frankel-Romer gravitybased measure of exogenous openness is added as an instrument) that our results remain the same with different sets of instruments. Actually, we find in unreported regressions similar to Table 7 in LMW, that many permutations in the set of instruments lead to the same conclusion, namely a strong significance of both health variables. In addition, the following subsection will provide additional evidence on the robustness of our results using a different strategy than the instrumental approach.

Lastly, we investigate whether the effect of health variables upon economic growth can be decomposed into various channels such as the level of investment 
into physical or human capital as well as the level of fertility. Echoing LMW Table A4, we find on Table 4 columns 7 to 9 that the initial level of life expectancy has a positive impact on the average rates of investment in both physical capital and secondary schooling, while both the growth and the initial level of life expectancy help reducing the level of fertility. As a sum, health variables can be seen as robust determinants of economic growth, and this finding is insensitive to various changes in the choice of instruments.

Table 4 - Robustness Analysis with Respect to Explanatory Variables and Instruments

\begin{tabular}{|c|c|c|c|c|c|c|c|c|c|}
\hline & \multicolumn{6}{|c|}{ Reduced-form growth regression } & \multicolumn{3}{|c|}{ Detailed channels } \\
\hline & \multicolumn{6}{|c|}{ Dependent variable: Annualized growth in GDP per capita 1960-2000 } & \multirow{3}{*}{$\begin{array}{c}\text { Average } \\
\text { investment } \\
\text { share } \\
\text { of GDP } \\
\text { IV=ME+ } \\
\text { (7) }\end{array}$} & \multirow{3}{*}{$\begin{array}{c}\text { Average } \\
\text { enrollment } \\
\text { rate at } \\
\text { secondary }\end{array}$} & \multirow{3}{*}{$\begin{array}{c}\text { Average } \\
\text { total } \\
\text { fertility } \\
\text { rate }\end{array}$} \\
\hline & OLS & OLS & $\begin{array}{c}\text { IV }=\text { ME }+ \\
\text { Geography+ }\end{array}$ & $\begin{array}{c}\text { IV }=\text { ME+ } \\
\text { Geography+ }\end{array}$ & $\begin{array}{l}\text { IV=ME }+ \\
\text { Climate }\end{array}$ & $\begin{array}{c}\text { IV }=\mathrm{ME}+ \\
\text { Geography+ }\end{array}$ & & & \\
\hline & (1) & (2) & $\begin{array}{l}\text { Climate } \\
\text { (3) }\end{array}$ & $\begin{array}{c}\text { Climate } \\
\text { (4) }\end{array}$ & (5) & $\begin{array}{c}\text { Climate+FR } \\
\text { (6) }\end{array}$ & & & \\
\hline $\begin{array}{l}\text { Growth in log life } \\
\text { expectancy } 1960-2000\end{array}$ & $\begin{array}{c}154.200 * * * \\
\quad(38.32)\end{array}$ & $\begin{array}{c}119.837^{* * *} \\
\quad(35.17)\end{array}$ & $\begin{array}{l}184.489 * * * \\
(55.26)\end{array}$ & $\begin{array}{l}153.023^{* * *} \\
(49.04)\end{array}$ & $\begin{array}{c}142.806 \ddagger \\
(60.10)\end{array}$ & $\begin{array}{c}158.720^{* * *} \\
(51.47)\end{array}$ & $\begin{array}{l}247.076 \\
(259.66)\end{array}$ & $\begin{array}{l}3.060 \\
(3.03)\end{array}$ & $\begin{array}{c}-100.188^{* * *} \\
(35.38)\end{array}$ \\
\hline $\begin{array}{l}\text { Initial log life expectancy } \\
1960\end{array}$ & $\begin{array}{c}7.823^{* * *} \\
(0.93)\end{array}$ & $\begin{array}{c}6.876^{* * *} \\
(1.05)\end{array}$ & $\begin{array}{l}9.103^{* * *} \\
(1.12)\end{array}$ & $\begin{array}{c}8.371^{* * *} \\
(1.40)\end{array}$ & $\begin{array}{c}9.433^{* * *} \\
(1.56)\end{array}$ & $\begin{array}{c}8.027^{* * *} \\
(1.58)\end{array}$ & $\begin{array}{l}22.568^{* * * *} \\
(6.29)\end{array}$ & $\begin{array}{c}0.564^{* * *} \\
(0.11)\end{array}$ & $\begin{array}{c}-6.788^{* * *} \\
(1.09)\end{array}$ \\
\hline $\begin{array}{l}\text { Initial log GDP per capita } \\
1960\end{array}$ & $\begin{array}{l}-1.145^{* * *} \\
(0.22)\end{array}$ & $\begin{array}{c}-1.186^{* * *} \\
(0.24)\end{array}$ & $\begin{array}{c}-1.412^{* * *} \\
(0.26)\end{array}$ & $\begin{array}{c}-1.183^{* * *} \\
(0.27)\end{array}$ & $\begin{array}{c}-1.195^{* * *} \\
(0.26)\end{array}$ & $\begin{array}{c}-1.088^{* * *} \\
(0.28)\end{array}$ & $\begin{array}{l}-2.452 \\
(1.54)\end{array}$ & $\begin{array}{l}0.011 \\
(0.03)\end{array}$ & $\begin{array}{l}-0.125 \\
(0.16)\end{array}$ \\
\hline Democracy index & --- & $\begin{array}{l}0.225 \\
(0.50)\end{array}$ & --- & $\begin{array}{l}0.707 \\
(0.65)\end{array}$ & $\begin{array}{l}1.180^{*} \\
(0.70)\end{array}$ & $\begin{array}{l}0.789 \\
(0.72)\end{array}$ & $\begin{array}{l}3.769 \\
(3.25)\end{array}$ & $\begin{array}{l}-0.033 \\
(0.05)\end{array}$ & $\begin{array}{l}-0.141 \\
(0.55)\end{array}$ \\
\hline Urbanization rate & --- & $\begin{array}{l}0.008 \\
(0.01)\end{array}$ & --- & $\begin{array}{l}0.001 \\
(0.01)\end{array}$ & $\begin{array}{l}-0.003 \\
(0.01)\end{array}$ & $\begin{array}{l}-0.00 \\
(0.01)\end{array}$ & $\begin{array}{l}0.051 \\
(0.06)\end{array}$ & $\begin{array}{l}0.001 \\
(0.00)\end{array}$ & $\begin{array}{l}0.007 \\
(0.01)\end{array}$ \\
\hline Population density & -- & $\begin{array}{l}0.640 \\
(1.08)\end{array}$ & --- & $\begin{array}{l}-0.125 \\
(1.15)\end{array}$ & $\begin{array}{l}-0.138 \\
(1.14)\end{array}$ & $\begin{array}{l}-0.511 \\
(1.25)\end{array}$ & $\begin{array}{l}-3.974 \\
(5.33)\end{array}$ & $\begin{array}{l}0.137^{*} \\
(0.08)\end{array}$ & $\begin{array}{c}-1.388^{* *} \\
(0.55)\end{array}$ \\
\hline Openness & --- & $\begin{array}{c}0.046^{* * *} \\
(0.01)\end{array}$ & --- & $\begin{array}{c}0.043^{* * *} \\
(0.01)\end{array}$ & $\begin{array}{c}0.049 * * * \\
(0.02)\end{array}$ & $\begin{array}{c}0.102 * * \\
(0.05)\end{array}$ & --- & --- & --- \\
\hline Log of population & --- & $\begin{array}{c}0.421^{* * *} \\
(0.11)\end{array}$ & --- & $\begin{array}{c}0.425^{* * *} \\
(0.12)\end{array}$ & $\begin{array}{c}0.453^{* * *} \\
(0.13)\end{array}$ & $\begin{array}{c}0.790^{* *} \\
(0.32)\end{array}$ & --- & --- & --- \\
\hline $\begin{array}{l}\text { Log of population } \times \\
\text { Openness }\end{array}$ & --- & $\begin{array}{c}-0.004^{* *} \\
(0.00)\end{array}$ & --- & $\begin{array}{c}-0.003^{* *} \\
(0.00)\end{array}$ & $\begin{array}{c}-0.004^{* *} \\
(0.00)\end{array}$ & $\begin{array}{c}-0.010^{*} \\
(0.01)\end{array}$ & --- & --- & --- \\
\hline $\mathrm{N}$ & 96 & 95 & 90 & 90 & 91 & 91 & 97 & 88 & 96 \\
\hline
\end{tabular}

Notes: this table is based on LMW Tables 5, 7 and A4. It presents the causal effect of life expectancy on economic growth as well as on three fundamental determinants of growth, namely the rate of investment, the enrollment ratio and the fertility rate. The logic is as follows: 1) ME, geographical and climatic variables affect health. 2) together with a set of other variables $A=$ (democracy, urbanization, population density), health affects the investment rate, the enrollment rate and the fertility rate, and consequently economic growth. 3) in a reduced-form framework, per capita GDP growth is therefore regressed on subset A as well as health variables in columns ( 1 to 6 ). Openness and its interaction with population (instrumented on column 6) are added to capture policy variables. 4) complementary information is given by columns 7-8-9 where the three fundamental channels of economic growth are regressed upon subset $A$ and health variables. Robust standard errors; ${ }^{* *}$ (respectively ${ }^{* *}$ and ${ }^{*}$ ) represents significance at $1 \%$ (resp. $5 \%$ and $10 \%)$;

\subsection{Bayesian Analysis of the Endogeneity Bias}

An alternative way from the IV strategy to assess the influence of endogeneity issues in OLS regressions, is to use Bayesian econometrics as suggested recently by Conley et al. (2008) as well as Kraay $(2008,2010)$. The idea is to acknowledge the potential existence of an endogeneity bias by setting some prior on the magnitude of this bias, and then to measure the influence of this prior on the estimates of the coefficients of interest. This method generalizes a pure OLS 
approach, which relies on the implicit (degenerate) prior that the correlation between residuals and regressors is equal to zero with probability one.

Consider again equation (4), and let us center all variables and standardize the two explanatory variables, which results in estimating the linear model

$$
y=X \beta+u
$$

where $X$ denotes the matrix containing normalized growth and initial level in life expectancy. Then, let us assume joint normality for $X$ and $u$, let us denote by $\rho$ the $2 \times 1$ vector of correlations between the two regressors and the residuals, by $R$ the $2 \times 2$ covariance matrix of regressors, and by $s^{2}$ the variance of residuals. Assume also uninformative or diffuse prior distributions for $\beta$ and $s^{2}$, but a nondegenerate prior for $\rho$.

The magnitude and sign of the correlation between residuals and regressors are a priori ambiguous. For example, unobserved factors that relate to health standards, may be positively correlated with both health outcome variables and growth of per capita GDP, thereby producing a positive $\rho$. However, while unobserved factors linked to technology (including health technology) or income standards may be positively correlated with health outcome variables, hey might be negatively correlated with per capita GDP growth as a result of (crosscountry) income convergence. This in turn will tend to generate a negative $\rho$. Overall, let us assume in a first step that each component of $\rho$ is uniformly and independently distributed on the interval $[-r, r]$ with $r>0$. This generalizes the usual approach of assuming a mass point for each component of $\rho$ at $r=0$.The objective function for Bayesian estimation is the posterior distribution $p((\beta, \sigma, \rho) / Z)$ set over parameters $(\beta, \sigma, \rho)$ conditional upon the observations on $Z=(y, Z)$. Bayes rule implies that this posterior distribution is proportional to the product of the likelihood with the prior distributions. In this application, we are interested by the marginal posterior distribution for $\beta, p(\beta / Z)$ which is equal to the posterior distribution $p((\beta, \sigma, \rho) / Z)$ averaged over $\sigma$ and $\rho$ Because we did not select conjugate priors, the marginal posterior distribution $p(\beta / Z)$ has no closed-form expression. However, as in Kraay $(2008,2010)$, one can compute its first two moments. ${ }^{23}$ Performing some rearrangements and making repeated use of the law of iterated expectations, yields both the average and the variance of the posterior distribution $p(\beta / Z)$, from which one can compute a coefficient of variation. ${ }^{24}$ Significance is then evaluated by comparing the coefficient of variation with some significance threshold. Noticing $\hat{\beta}$ and $\hat{s}^{2}$ for the OLS estimates, one has

${ }^{23}$ Kraay (2010) considers the case of IV estimation in which there are violations of the exclusion restriction. It is based on Kraay (2008), which also discusses the OLS case where the regressor is correlated with the error term, as in the current section.

${ }^{24}$ We thank David Roodman and Aart Kraay for sharing these preliminary results from their ongoing work on the interactions between multicollinearity and endogeneity. 


$$
\begin{gathered}
E_{\rho}(\beta)=\hat{\beta}-\hat{s}^{2} \frac{\Gamma((N-K-1) / 2)}{\Gamma((N-K) / 2)} \sqrt{\frac{N-K}{2}} E_{\rho}\left(\frac{R^{-1} \rho}{\sqrt{1-\rho^{\prime-1} \rho}}\right) \\
V_{\rho}(\beta)=\hat{s}^{2}\left(X^{\prime-1}+\frac{N-K}{N-K-2}\right) E_{\rho}\left(\frac{R^{-1} \rho \rho^{\prime-1}}{1-\rho^{\prime-1} \rho}\right)
\end{gathered}
$$

Expectations can be evaluated by Monte-Carlo simulations. As a convenient threshold of significance, we select a coefficient of variation equal to $1 / 1.96=0.51$ in analogy to the Gaussian case. ${ }^{25}$

Figure 3 describes the resulting coefficient of variation for $\beta$ with respect to $r$ the maximum level of the endogenous correlation. We find that the coefficient of initial life expectancy appears to be significant (and positive) for a large range of correlations between residuals and regressors spanning the [0, 0.44] interval. For growth of life expectancy, the estimate becomes insignificant when the magnitude of endogeneity exceeds a level of correlation of about 0.17 .

Figure 3 - Robustness Analysis on Parameters Estimates with Respect to Endogeneity Bias

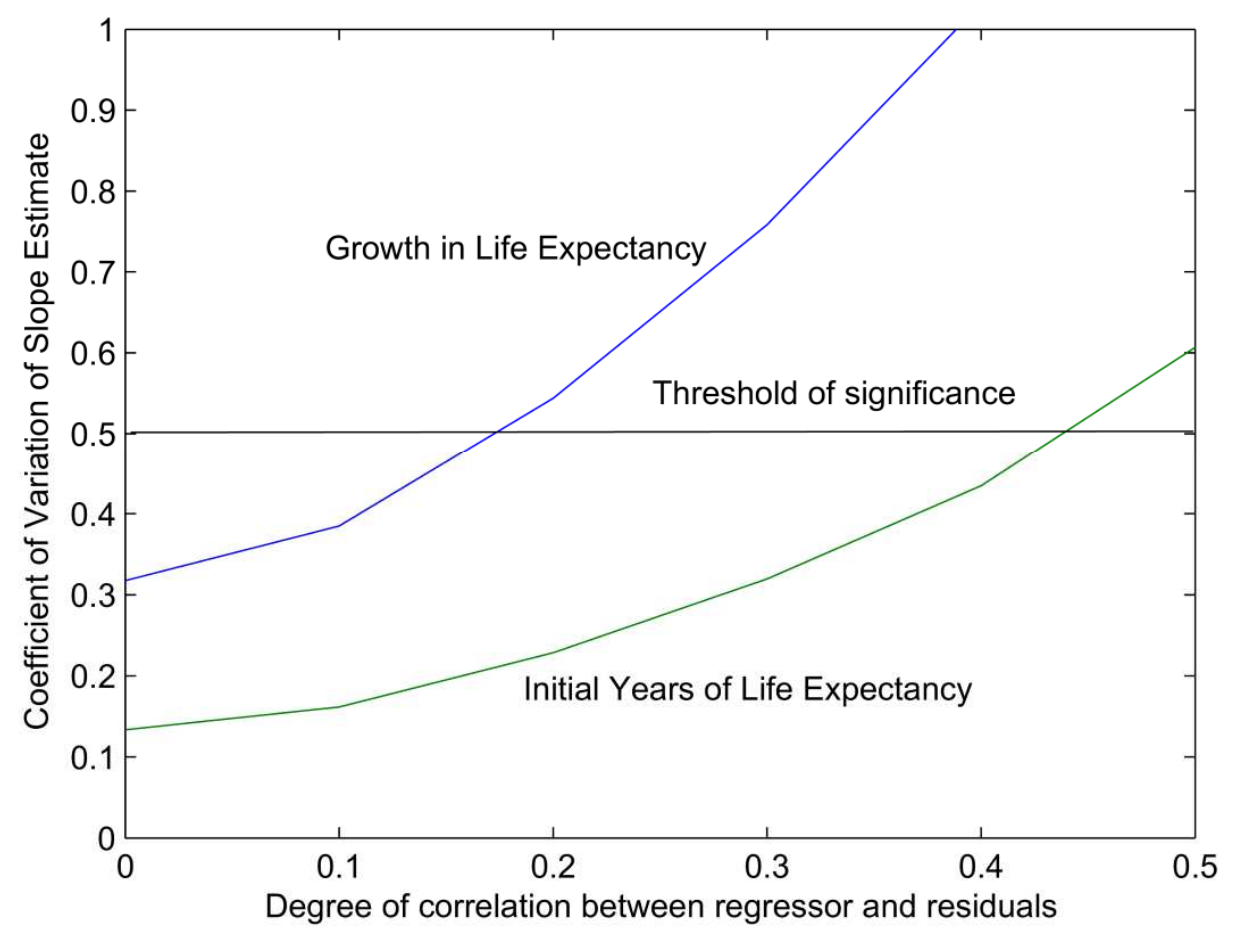

${ }^{25}$ The marginal posterior distribution of $\beta$ is not necessarily gaussian due to the nondegenerate prior set on $\rho$, but differences with the gaussian case arising from skewness and excess kurtosis are deemed to be small. Also, the positivity of $1-\rho^{\prime-1} \rho$ has been checked empirically. 
In addition, our findings are unchanged when we consider other priors for the endogeneity bias. For instance, results are qualitatively identical when assuming a single endogenous regressor (growth in life expectancy) rather than two. Also, we used uniform distributions on $[0, r]$, assuming strictly positive correlations and systematic overestimation of $\beta$, which is the most adverse case regarding the significance of the true estimate. Again, initial life expectancy was significant for $r<0.25$, and growth in life expectancy was significant for $r<0.08$.

Summing up, this analysis suggests that the initial level of life expectancy is a robust and positive determinant of per capita GDP growth for a large range of potential endogeneity distortions. Growth of life expectancy is a less robust determinant, as already suggested by IV estimates (Table 3 column V).

\subsection{Growth and Life Expectancy by Age in OECD Countries}

In unreported regressions, we found that the correlations between productivity growth and the level and growth rate in life expectancy in OECD are weak in the post-1960 period. This is not surprising: first, cross-OECD differences in life expectancy are too small in 1960 to generate significant coefficients when regressing (per capita GDP) growth over the level and growth of life expectancy over the post-1960 period. Indeed, in 1960, 24 OECD countries out of 28 would show a life expectancy at birth which lies between 67.6 and 73.4 years. ${ }^{26}$ Second, the coefficient of life expectancy growth in the combined regression, was found to be significant only at 10\% over the 1960-1990 period, and it is insignificant over the period between 1960 and 2000 when controlling for initial log of per capita GDP. We interpret this finding as evidence that the relationship between health and growth has weakened after 1960, and that not all of the post-1960 gains in life expectancy have had a significant impact on productivity growth. More precisely, we hypothesize that gains in life expectancy at young age and during active life matter more than gains in life expectancy at old-age.

To test this latter hypothesis, we use the OECD (2009) health database and exploit its panel dimension to increase the sample size and thereby improve statistical robustness. This comes at the cost of losing the former instrumentation procedure, as all of our instruments that are relevant over that period are timeconstant. However, all former IV estimates were relatively close to their OLS counterparts, which in turn suggests that OLS regressions already reflect the causal effects we are trying to uncover. Besides, we can rely on GMM for an instrumentation with lagged explanatory variables.

Thus, Table 5 regresses the log of per capita GDP on variables measuring life expectancy at various ages (respectively at age 0, 40,60 and 80). The retained time span is ten years and all regressions include time effects. As shown by the results, each explanatory variable in isolation comes out significant except life expectancy at 80 years when introducing fixed-effects. However, when

\footnotetext{
${ }^{26}$ Differences were relatively much starker in 1940: within the set of 22 OECD countries available both in 1940 and 1960, the coefficient of variation of life expectancy was equal to $11.5 \%$ in 1940 versus $6.9 \%$ twenty years later.
} 
regressing log per capita GDP on all life expectancy variables simultaneously, we find that life expectancy at age equal or older than 40 years is not significant. In other words, only gains in life expectancy below 40 years are significantly correlated with per capita GDP growth.

Table 5 - Life Expectancy and GDP per Capita - OECD Countries 1960-2000 (Decennial Time Span)

\begin{tabular}{|c|c|c|c|c|c|c|c|c|c|c|}
\hline & \multicolumn{5}{|c|}{ Pooled OLS } & \multicolumn{5}{|c|}{ Panel Fixed-Effects } \\
\hline & $\mathrm{I}$ & II & III & IV & v & $\mathrm{VI}$ & VII & VIII & IX & $\mathrm{x}$ \\
\hline & \multicolumn{10}{|c|}{ Dependent variable: Log GDP per Capita } \\
\hline Log of life expectancy at birth & $\begin{array}{c}7.19 * * * \\
(0.55)\end{array}$ & --- & --- & & $\begin{array}{c}10.72 * * * \\
(2.78)\end{array}$ & $\begin{array}{c}4.40^{* * *} \\
(0.54)\end{array}$ & --- & --- & --- & $\begin{array}{c}8.57^{* * *} \\
(1.27)\end{array}$ \\
\hline Log of life expectancy at 40 & --- & $\begin{array}{c}4.84^{* * * *} \\
(0.92)\end{array}$ & --- & & $\begin{array}{l}-2.77 \\
(4.70)\end{array}$ & --- & $\begin{array}{c}2.45^{* * *} \\
(0.72)\end{array}$ & --- & --- & $\begin{array}{l}-1.63 \\
(0.50)\end{array}$ \\
\hline Log of life expectancy at 60 & --- & --- & $\begin{array}{c}3.51^{* * *} \\
(0.68)\end{array}$ & & $\begin{array}{l}-1.44 \\
(2.80)\end{array}$ & --- & --- & $\begin{array}{c}1.47^{* * *} \\
(0.52)\end{array}$ & --- & $\begin{array}{l}-0.86 \\
(1.83)\end{array}$ \\
\hline Log of life expectancy at 80 & --- & --- & --- & $\begin{array}{c}2.73^{* * *} \\
(0.48)\end{array}$ & $\begin{array}{c}1.75^{* *} \\
(0.82)\end{array}$ & --- & --- & --- & $\begin{array}{c}0.54 \\
(0.39)\end{array}$ & $\begin{array}{l}-0.16 \\
(0.51)\end{array}$ \\
\hline Time dummies & Yes & Yes & Yes & Yes & Yes & Yes & Yes & Yes & Yes & Yes \\
\hline Country fixed-effects & No & No & No & No & No & Yes & Yes & Yes & Yes & Yes \\
\hline $\mathrm{R} 2$ & 0.77 & 0.66 & 0.67 & 0.69 & 0.79 & 0.73 & 0.61 & 0.59 & 0.52 & 0.69 \\
\hline $\mathrm{N}$ & 125 & 120 & 120 & 113 & 113 & 125 & 120 & 120 & 113 & 113 \\
\hline $\mathrm{N}$ countries & 28 & 28 & 28 & 28 & 28 & 28 & 28 & 28 & 28 & 28 \\
\hline
\end{tabular}

Source: Life expectancy by age: OECD Health data (2008); GDP per capita: World Bank (2004); Robust standard errors; ${ }^{* * *}$ (respectively ${ }^{* *}$ and ${ }^{*}$ ) represents significance at $1 \%$ (resp. $5 \%$ and $\left.10 \%\right)$.

Finally, Table 6 replicates the former regressions using the SYS-GMM estimator as described by Blundell-Bond (1998). In order to reduce the autocorrelation of residuals and eliminate potentially non-stationary components, here we first-differentiate the dependent and explanatory variables, regressing decennial growth of per capita GDP on growth of life expectancy over a ten years period, ${ }^{27}$ controlling for time dummies and country fixed effects. We still get the same conclusions, namely that reduced mortality between age zero and forty has a positive and significant impact on per capita GDP growth. ${ }^{28}$ Our results are in line with the empirical microeconomic literature showing that better health at young age has long-term consequences in terms of workers productivity. ${ }^{29}$

\footnotetext{
${ }^{27}$ We use log life expectancy lagged 20, 30 and 40 years as instrumental variables. All results remain identical when using variables in levels rather than in difference, but in the former case specification tests detect autocorrelation in residuals.

${ }^{28}$ The latter regression correctly rejects the null hypothesis of zero first-order correlation of first-differenced residuals, and correctly accepts the null hypothesis of zero secondorder autocorrelation. A Hansen test of overidentifying restrictions validates the null hypothesis of joint exogeneity of instruments. As underlined by Roodman (2009), the number of instruments has been reduced in order to avoid the instruments proliferation problem that leads to Hansen statistics overestimation.

${ }^{29}$ See Behrman-Rosenzweig (2004) and Black et al. (2007).
} 
Table 6 - Life Expectancy by Age and GDP per Capita - OECD Countries 1960-2000

\begin{tabular}{|c|c|c|c|c|c|}
\hline & & & SYS-GMN & & \\
\hline & 1 & II & III & IV & $\mathrm{V}$ \\
\hline & Depend & nt varia & : Growt & n GDP p & Capita \\
\hline Growth in life expectancy at birth & $\begin{array}{c}2.88^{* * *} \\
(1.08)\end{array}$ & --- & --- & --- & $\begin{array}{c}9.46^{* *} \\
(4.41)\end{array}$ \\
\hline Growth in life expectancy at 40 & --- & $\begin{array}{l}3.62 * \\
(1.88)\end{array}$ & --- & --- & $\begin{array}{c}-5.37 \\
(8.02)\end{array}$ \\
\hline Growth in life expectancy at 60 & --- & --- & $\begin{array}{c}2.02^{* *} \\
(0.84)\end{array}$ & --- & $\begin{array}{c}2.61 \\
(4.79)\end{array}$ \\
\hline Growth in life expectancy at 80 & --- & --- & --- & $\begin{array}{c}0.09 \\
(0.55)\end{array}$ & $\begin{array}{l}-0.78 \\
(0.68)\end{array}$ \\
\hline Time dummies & Yes & Yes & Yes & Yes & Yes \\
\hline Country fixed-effects & Yes & Yes & Yes & Yes & Yes \\
\hline $\mathrm{N}$ & 97 & 90 & 90 & 82 & 82 \\
\hline $\mathrm{N}$ countries & 28 & 27 & 27 & 27 & 27 \\
\hline $\mathrm{N}$ instruments & 13 & 13 & 13 & 13 & 13 \\
\hline Arellano-Bond 1st order correlation ( $p$-value) & 0.20 & 0.25 & 0.22 & 0.07 & 0.05 \\
\hline Arellano-Bond 2 nd order correlation ( $p$-value) & 0.99 & 0.61 & 0.42 & 0.36 & 0.84 \\
\hline Hansen-J test & 0.18 & 0.30 & 0.39 & 0.64 & 0.88 \\
\hline
\end{tabular}

\section{Conclusions}

In this paper we argued that combining the Lucas (1988) and Nelson-Phelps (1966) approaches to human capital improves our understanding of the relationship between health and growth. We first provided a simple model where both the initial level and the accumulation of health matter for growth. Then, in our empirical cross-country analysis over the period 1960-2000, using the same instruments for health as Lorentzen-McMillan-Wacziarg (2008), we found that better life expectancy, in the sense of both a higher initial level and faster growth, is growth-enhancing. However, a Bayesian robustness analysis suggests that initial life expectancy is a more robust determinant than the growth of life expectancy. Then, looking more closely at life expectancy at various ages in OECD countries, we found that reducing mortality below age 40 is particularly growth-enhancing.

This research could be extended in several directions. One direction would be to look at the growth effects of particular diseases, thereby leading to a reassessment of the costs and benefits of curing those diseases. Another extension would be to investigate the main channels through which health affects growth. These and other extensions of the analysis in this paper are left for future research. 


\section{References}

Acemoglu, D., \& Johnson, S. (2007). Disease and Development: the Effect of Life Expectancy on Economic Growth. Journal of Political Economy, 115(6), 925-985. doi:10.1086/529000.

Ashraf, Q. H., Lester, A., \& Weil, D.N. (2008). When Does Improving Health Raise GDP? In Acemoglu, D., Rogoff, K., \& Woodford, M. (Eds.). (2009). Macroeconomics Annual 2008. University of Chicago Press.

Becker, G.S., Philipson, T.J., \& Soares, R.R. (2005). The Quantity and Quality of Life and the Evolution of World Inequality. American Economic Review, 95(1), 277-91. doi:10.1257/0002828053828563

Behrman, J.R., \& Rosenzweig, M.R. (2004). Returns to Birthweight. The Review of Economics and Statistics, 86(2), 586-601. doi:10.1162/003465304323031139

Black, S.E., Devereux, P.J., \& Salvanes, K.G. (2007). From the Cradle to the Labor Market? The Effect of Birth Weight on Adult Outcomes. Quarterly Journal of Economics, 122(1), 409-439. doi:10.1162/qjec.122.1.409

Bleakley, H. (2003). Disease and Development: Evidence from the American South. Journal of the European Economic Association, 1(2-3), 376-386. doi:10.1162/154247603322391017

Bleakley, H. (2007). Disease and Development: Evidence from Hookworm Eradication in the American South. Quarterly Journal of Economics, 122(1), 73117. doi:10.1162/qjec.121.1.73

Bleakley, H., \& Lange, F. (2009). Chronic Disease Burden and the Interaction of Education, Fertility and Growth. Review of Economics and Statistics, 91(1), 52-65. doi:10.1162/rest.91.1.52

Blundell, R., \& Bond, S. (1998). Initial Conditions and Moment Restrictions in Dynamic Panel Data Models. Journal of Econometrics, 87(1), 115-143. doi:10.1016/S0304-4076(98)00009-8

Cervellati, M. and U. Sunde (2009). Life Expectancy and Economic Growth: The Role of the Demo- graphic Transition. IZA Discussion Papers 4160. Bonn: Institute for the Study of Labor (IZA).

Conley, T., Hansen, C., \& Rossi, P.E. (2008). Plausibly Exogenous. Mimeo. Graduate School of Business, University of Chicago.

Doppelhofer, G., Miller, R., \& Sala-I-Martin, X. (2004). Determinants of LongTerm Growth: A Bayesian Averaging of Classical Estimates (BACE) Approach. American Economic Review, 94(4), 813-835. doi:10.1257/0002828042002570

Galor, O. (2005). The Demographic Transition and the Emergence of Sustained Economic Growth. Journal of the European Economic Association, 3(2-3), 494-504. doi:10.1162/jeea.2005.3.2-3.494

Hauk, W.R., \& Wacziarg, R. (2009). A Monte Carlo Study of Growth Regressions. Journal of Economic Growth, 14(2), 103-147. doi:10.1007/s10887-009-9040-3 
Howitt, P. (2005). Health, Human Capital, and Economic Growth: A Schumpeterian Perspective. In López-Casasnovas, G., Rivera, B., \& Currais, L. (Eds.). (2005). Health and Economic Growth: Findings and Policy Implications (pp. 19-40). Cambridge, MA: MIT Press.

Jayachandran, S., \& Lleras-Muney, A. (2009). Life Expectancy and Human Capital Investments: Evidence from Maternal Mortality Declines. Quarterly Journal of Economics, 124(1), 349-397. doi:10.1162/ qjec.2009.124.1.349

Kraay, A. (2008). Instrumental Variables Regressions with Honestly Uncertain Exclusion Restrictions. Policy Research Working Paper Series 4632. Washington, DC: The World Bank.

Kraay, A. (2010). Instrumental Variables Regressions with Honestly Uncertain Exclusion Restrictions. Journal of Applied Econometrics, 1099-1255. doi:10.1002/jae.1148

Krueger, A.B., \& Lindahl, M. (2001). Education for Growth: Why and for Whom? Journal of Economic Literature, 39(4), 1101-1136.

Lee, R. (2003). The Demographic Transition: Three Centuries of Fundamental Change. Journal of Economic Perspectives, 17(4), 167-190. doi:10.1257/089533003772034943

Lorentzen, P., McMillan J., \& Wacziarg, R. (2008). Death and Development. Journal of Economic Growth, 13(2), 81-124. doi:10.1007/s10887-008-9029-3

Lucas, R. (1988). On the Mechanics of Economic Development. Journal of Monetary Economics, 22(1), 3-42. doi:10.1016/0304-3932(88)90168-7

Mankiw, N.G., Romer D., \& Weil, D. (1992). A Contribution to the Empirics of Growth. Quarterly Journal of Economics, 107(2), 407-437. doi:10.2307/2118477

Miguel, E., \& Kremer, M. (2004).Worms: Identifying Impacts on Education and Health in the Presence of Treatment Externalities. Econometrica, 72(1), 159-217. doi:10.1111/j.1468-0262.2004.00481.x

Morrisson, C., \& Murtin, F. (2009). The Century of Education. Journal of Human Capital, 3(1), 1-42. doi:10.1086/600102

Murtin, F. (2009). On the Demographic Transition 1870-2000. Paris School of Economics working paper.

Nelson, R., \& Phelps, E. (1966). Investment in Humans, Technological Diffusion, and Economic Growth. American Economic Review, 56(1-2), 69-75.

Roodman, D. (2009). A Note on the Theme of Too Many Instruments. Oxford Bulletin of Economics and Statistics, 71(1), 135-58. doi:10.1111/j.1468$\underline{0084.2008 .00542 . x}$

Sachs, J., Kiszewski, A., Mellinger, A., Spielman A., Malaney, P., \& Ehrlich, S. (2004). A Global Index of the Stability of Malaria Transmission. American Journal of Tropical Medicine and Hygiene, 70(5), 486-98.

Weil, D. (2007). Accounting for the Effect of Health on Economic Growth. Quarterly Journal of Economics, 122(3), 1265-1306. doi:10.1162/qjec.122.3.1265 
Zhang, J., Zhang, J., \& Lee, R. (2003). Rising Longevity, Education, Savings, and Growth. Journal of Development Economics, 70 (1), 83-101. doi:10.1016/S03043878(02)00088-3 